3. Fenton PJ, Gardner ID. Simultaneous bilateral intraocular surgery. Trans Ophthalmol Soc UK. 1982;102:298-301.

4. Schachat AP. Simultaneous bilateral endophthalmitis after immediate sequential bilateral cataract surgery: what's the risk of functional blindness? Am J Ophthalmol. 2014;158:410-1.

5. Chu CJ, et al. Risk Factors and Incidence of Macular Edema after Cataract Surgery A Database Study of 81984 Eyes. Ophthalmology. 2016;123:316-323.
6. Masood I, Negi A, Vernon SA, et al. The $-174 \mathrm{G} / \mathrm{C}$ interleukin-6 promoter polymorphism influences the development of macular oedema following uncomplicated phacoemulsification surgery. Eye. 2007;21:1412-5.

7. McCafferty S, et al. Pseudophakic cystoid macular edema prevention and risk factors; prospective study with adjunctive once daily topical nepafenac $0.3 \%$ versus placebo. BMC Ophthalmol. 2017;17:16. 20

\title{
Foetal haemoglobin, blood transfusion, and retinopathy of prematurity
}

\author{
Luciana Teofili $\mathbb{D}^{1} \cdot$ Maria Bianchi ${ }^{1} \cdot$ Antonio Baldascino $^{2} \cdot$ Patrizia Papacci $^{3} \cdot$ Giovanni Vento $^{3}$
}

Received: 3 September 2017 / Accepted: 1 November 2017 / Published online: 12 February 2018

(c) The Royal College of Ophthalmologists 2018

Stutchfield et al. have recently demonstrated that low foetal haemoglobin $(\mathrm{HbF})$ levels predict retinopathy of prematurity (ROP) [1]. There is an increasing awareness that red blood cell (RBC) transfusions are independent risk factors for all prematurity-associated diseases (PAD) [2]. Since adult haemoglobin $(\mathrm{HbA})$ releases oxygen more efficiently than $\mathrm{HbF}$, autologous cord blood (CB) transfusion has been attempted, with limited results due to the low volume of $\mathrm{CB}$ collected [3]. We have shown that allogeneic $\mathrm{CB}$ RBC concentrates obtained from healthy full-term babies can fulfil transfusion requirements of preterm neonates (PNs) with gestational age $\leq 30$ weeks and/or birth weight $\leq 1500 \mathrm{~g}$, in their first 28 days of life [4]. At first transfusion episode, $\mathrm{PNs}$ received $\mathrm{ABO}-\mathrm{Rh}(\mathrm{D})$ matched CB-RBCs if available, or adult RBCs if CB units were not available. At subsequent transfusions, the same regimen was adopted, unless CB-RBCs were unavailable. Overall, 9 patients received CB-RBCs and 11 adult-RBCs; 6 patients ( 3 in each group) died before ROP assessment. Table 1 illustrates ROP findings in 14 surviving patients. All PNs

Luciana Teofili

luciana.teofili@unicatt.it

1 Transfusion Medicine Department, Fondazione Policlinico Universitario A. Gemelli-Università Cattolica del Sacro Cuore, Roma, Italy

2 Ophtalmology Department, Fondazione Policlinico Universitario A. Gemelli-Università Cattolica del Sacro Cuore, Roma, Italy

3 Neonatal Intensive Care Unit, Fondazione Policlinico Universitario A. Gemelli-Università Cattolica del Sacro Cuore, Roma, Italy receiving adult-RBCs developed ROP, while two of six patients in the CB-RBC group did not. Stage 3 ROP was observed in four heavily transfused extremely PNs: three of them were transfused only or mainly with adult-RBCs (patients 8,10 and 14, respectively; Table 1).

Transfusions contribute to the overwhelming oxidative burden caused by infections, oxygen therapy and inflammatory diseases in PNs. Unfortunately, to monitor in these patients lipid peroxidation products or other biomarkers of the oxidative stress, requires sophisticated methodologies and exceeding volume of biologic samples. Hence, these investigations are so far confined to the research field [5]. In this regard, the study of Stutchfield et al. suggests that monitoring $\mathrm{HbF}$ levels in PNs might be a feasible and reliable tool to figure out to what extent transfusions might favour PAD development.

Acknowledgements This study was supported by Genitin Onlus (Associazione Genitori Bambini Prematuri), Rome, Italy.

\section{Compliance with ethical standards}

Conflict of interest The authors declare that they have no competing interests.

\section{References}

1. Stutchfield CJ, Jain A, Odd D, Williams C, Markham R. Foetal haemoglobin, blood transfusion, and retinopathy of prematurity in very preterm infants: a pilot prospective cohort study. Eye (Lond). 2017;31:1451-1455. 
Table 1 ROP findings in preterm neonates receiving adult-RBC or CB-RBC transfusions

\begin{tabular}{llllll}
\hline Patients & $\begin{array}{l}\text { Gestational age } \\
\text { (weeks) }\end{array}$ & $\begin{array}{l}\text { Birth weight } \\
\text { (grams) }\end{array}$ & $\begin{array}{l}\text { ROP } \\
\text { (stage) }\end{array}$ & $\begin{array}{l}\text { Transfusion } \\
\text { regimen }\end{array}$ & $\begin{array}{l}\text { Number of } \\
\text { transfusions }\end{array}$ \\
\hline 1 & 30.7 & 1430 & No & Cord blood & 1 \\
2 & 28.1 & 860 & Yes (1) & Adult & 1 \\
3 & 23.3 & 580 & Yes (3) & Cord blood & 5 \\
4 & 27.3 & 1000 & Yes (1) & Adult & 1 \\
5 & 28.1 & 1170 & Yes (2) & Adult & 1 \\
6 & 26.6 & 860 & Yes (1) & Adult & 1 \\
7 & 27.6 & 700 & Yes (1) & Adult & 1 \\
8 & 26.1 & 650 & Yes (3) & Adult & 4 \\
9 & 27.6 & 1060 & Yes (2) & Adult & Adult \\
10 & 25.6 & 745 & Yes (3) & Cord blood & 4 \\
11 & 30.9 & 825 & No & Cord blood & 1 \\
12 & 26.0 & 570 & Yes (2) & Cord blood & 2 \\
13 & 27.1 & 910 & Yes (1) & Cord blood \\
14 & 28.4 & 770 & Yes (3) & $5^{\text {a }}$ \\
\hline
\end{tabular}

${ }^{\mathrm{a}}$ This patient received two $\mathrm{CB}-\mathrm{RBC}$ units and three adult-RBC units. Abbreviation as indicated in the text

2. dos Santos AM, Guinsburg R, de Almeida MF, Procianoy RS, Marba ST, Ferri WA, et al. Factors associated with red blood cell transfusions in very-low-birth-weight preterm infants in Brazilian neonatal units. BMC Pediatr. 2015;15:113.

3. Strauss RG, Widness JA. Is there a role for autologous/placental RBC transfusions in the anemia of prematurity? Transfus Med Rev. 2010;24:125-9.
4. Bianchi M, Giannantonio C, Spartano S, Fioretti M, Landini A, Molisso A, et al. Allogeneic umbilical cord blood red cell concentrates: an innovative blood product for transfusion therapy of preterm infants. Neonatology. 2015;107:81-6.

5. Torres-Cuevas I, Parra-Llorca A, Sánchez-Illana A, Nuñez-Ramiro A, Kuligowski J, Cháfer-Pericás $\mathrm{C}$, et al. Oxygen and oxidative stress in the perinatal period. Redox Biol. 2017;12:674-81.

\title{
In response to: Teofili $\mathrm{L}$, et al. Foetal haemoglobin, blood transfusion, and retinopathy of prematurity
}

\author{
Chris Stutchfield ${ }^{1,2} \cdot$ Anoo Jain $^{1} \cdot$ David Odd $^{2} \cdot$ Cathy Williams ${ }^{3,4} \cdot$ Richard Markham $^{3}$
}

Received: 31 October 2017 / Accepted: 1 November 2017 / Published online: 8 March 2018

(c) Royal College of Ophthalmologists 2018

We read the work of Teofili et al with interest. In our study we found an association between low foetal haemoglobin

Chris Stutchfield

cstutch@gmail.com

1 Neonatal Intensive Care Unit, St. Michael's Hospital Bristol, Bristol, UK

2 Neonatal Intensive Care Unit, Southmead Hospital, Bristol, UK

3 Bristol Eye Hospital, University Hospitals Bristol NHS Foundation Trust, Bristol, UK

4 School of Social and Community Medicine, University of Bristol, Bristol, UK levels $(\mathrm{HbF})$ levels and retinopathy of prematurity, but further work is required to identify a causal or predictive link. In addition, to optimising initial haemoglobin levels through delayed cord clamping when possible, managing anaemia with HbF-rich cord blood transfusions is an interesting proposition.

\section{Compliance with ethical standards}

Conflict of interest The authors declare that they have no conflict of interest. 